\title{
Preparation and characterization of nanosized lithium cobalt oxide powders for lithium-ion batteries
}

\author{
Chung-Hsin Lu*, Hsuan-Hao Chang, Yu-Kai Lin \\ Electronic and Electro-optical Ceramics Laboratory, Department of Chemical Engineering, National Taiwan University, Taipei, Taiwan, ROC
}

Received 29 November 2003; received in revised form 10 December 2003; accepted 22 December 2003

Available online 10 June 2004

\begin{abstract}
Lithium cobalt oxide powders have been synthesized by a developed microemulsion process in this study. The cationic concentration of the aqueous phase significantly affects the sizes of micelles and obtained powders. Increasing the cationic concentration of the aqueous phase leads the size of the micelles to increase. Nanosized and well dispersed $\mathrm{LiCoO}_{2}$ powders are obtained in this study. The electrochemical analysis reveals that the discharge capacity of $\mathrm{LiCoO}_{2}$ significantly depends on the particle size and agglomeration state of the synthesized powders.
\end{abstract}

(c) 2004 Elsevier Ltd and Techna Group S.r.l. All rights reserved.

Keywords: $\mathrm{LiCoO}_{2}$; Microemulsion; Nanoparticles; Lithium-ion batteries

\section{Introduction}

Lithium cobalt oxide $\left(\mathrm{LiCoO}_{2}\right)$ is one of the most important cathode materials used in lithium-ion secondary batteries. $\mathrm{LiCoO}_{2}$ can be prepared by various methods using different lithium and cobalt sources [1-3]. As all lithium ions are extracted from the host structure of $\mathrm{LiCoO}_{2}$, irreversible phase transformation will occur to result in inferior cycleability. When only $50 \%$ of the lithium ions are extracted during cycling, $\mathrm{LiCoO}_{2}$ can maintain good cyclic stability [4].

In recent years, synthesis of nanoparticles has been intensively investigated [5-7]. Powders prepared by the traditional solid-state reaction have large particle size and broad size distribution. On the other hand, solution method can reduce the particle size to nanometer range and control the particle size distribution. Different kinds of solution methods such as the sol-gel process [8], the hydrothermal process [9], and the emulsion process [10-12] have been utilized to synthesize the nanoparticles.

In lithium-ion batteries, cathode materials have great influence on the electrochemical performance. In this study, a newly developed microemulsion process is utilized to syn-

\footnotetext{
* Corresponding author. Tel.: +886-2-23635230; fax: +886-2-23623040

E-mail address: chlu@ccms.ntu.edu.tw (C.-H. Lu).
}

thesize $\mathrm{LiCoO}_{2}$ powders. The effects of the salinity in the aqueous phase and the heating conditions on the properties of synthesized powders are discussed. The electrochemical characteristics of $\mathrm{LiCoO}_{2}$ powders are also examined.

\section{Experimental}

Stoichiometric $\mathrm{LiNO}_{3}$ and $\mathrm{Co}\left(\mathrm{NO}_{3}\right)_{2} \cdot 6 \mathrm{H}_{2} \mathrm{O}$ were dissolved in water to form the aqueous phase. The salinity of the aqueous phase was varied from 0.5 to $2 \mathrm{M}$. The oil phase was comprised of analytical grade cyclohexane as the primary component. 1-Hexanol and OP-10 were chosen as the surfactant and co-surfactant, respectively. The well mixed water phase was added to the oil phase with a volume ratio maintained at 1:10. After thorough stirring, a thermodynamically stable microemulsion system was obtained. The prepared microemulsion was added dropwise to hot oil at $200{ }^{\circ} \mathrm{C}$ via a peristaltic pump. The obtained precursors were further dried at $400^{\circ} \mathrm{C}$ to remove organic phase. The dried powders were calcined at elevated temperatures for $2 \mathrm{~h}$ to obtain $\mathrm{LiCoO}_{2}$ powders. The microstructure of the calcined powders were examined by XRD and TEM, respectively. The size of microemulsion droplets was measured by an acoustic spectrometer. The electrochemical behavior of the obtained powders was examined in coin cells. The cathode composites were comprised of $87 \mathrm{wt} . \% \mathrm{LiCoO}_{2}$ powders, 
8 wt. \% super-S carbon black, and 5 wt.\% binder (polyvinylidene fluoride (PVdF)). $n$-Methyl pyrrolidone (NMP) was used as the solvent. Lithium foil was utilized as the anode, and the electrolyte solution was composed of $1 \mathrm{M} \mathrm{LiPF}_{6}$ dissolved in ethylene carbonate (EC)-dimethyl carbonate (DMC) (at a volume ratio of 1:1). The cells were charged and discharged at $0.2 \mathrm{~mA} / \mathrm{cm}^{2}$ within a potential range of 3 to $4.3 \mathrm{~V}$.

\section{Results and discussion}

\subsection{Formation of $\mathrm{LiCoO}_{2}$ powders}

Fig. 1 illustrates the variation of the X-ray diffraction patterns of the microemulsion-derived precursors quenched at temperature ranging from 500 to $900{ }^{\circ} \mathrm{C}$. The salinity of the aqueous phase in the precursors is $1 \mathrm{M}$. As shown in Fig. $1, \mathrm{LiCoO}_{2}$ is formed in $400{ }^{\circ} \mathrm{C}$ dried precursors. Once the temperature increases, the crystallinity of $\mathrm{LiCoO}_{2}$ is improved. During all heating processes, only $\mathrm{LiCoO}_{2}$ is obtained. The XRD pattern shows great consistency with that reported in JCPDS No. 44-151 [13], and the diffraction peaks in the XRD pattern have been indexed to the hexagonal form (high-temperature polymorph). Therefore, it confirms that the obtained $\mathrm{LiCoO}_{2}$ exhibits a $R \overline{3} \mathrm{~m}$ structure, and the pure phase of $\mathrm{LiCoO}_{2}$ is successfully obtained via the microemulsion process. In comparison with the conventional solid-state reaction [14], the required temperature for preparing $\mathrm{LiCoO}_{2}$ powders is significantly reduced in the microemulsion process. It is considered to result from

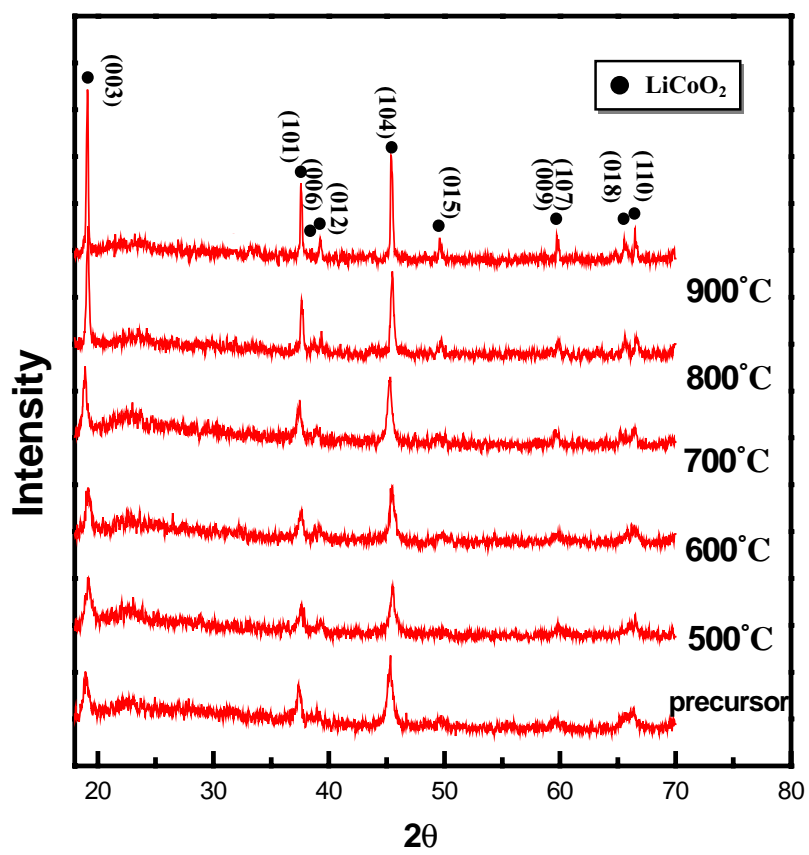

Fig. 1. XRD patterns of the microemulsion-derived $\mathrm{LiCoO}_{2}$ powders heated at elevated temperatures.

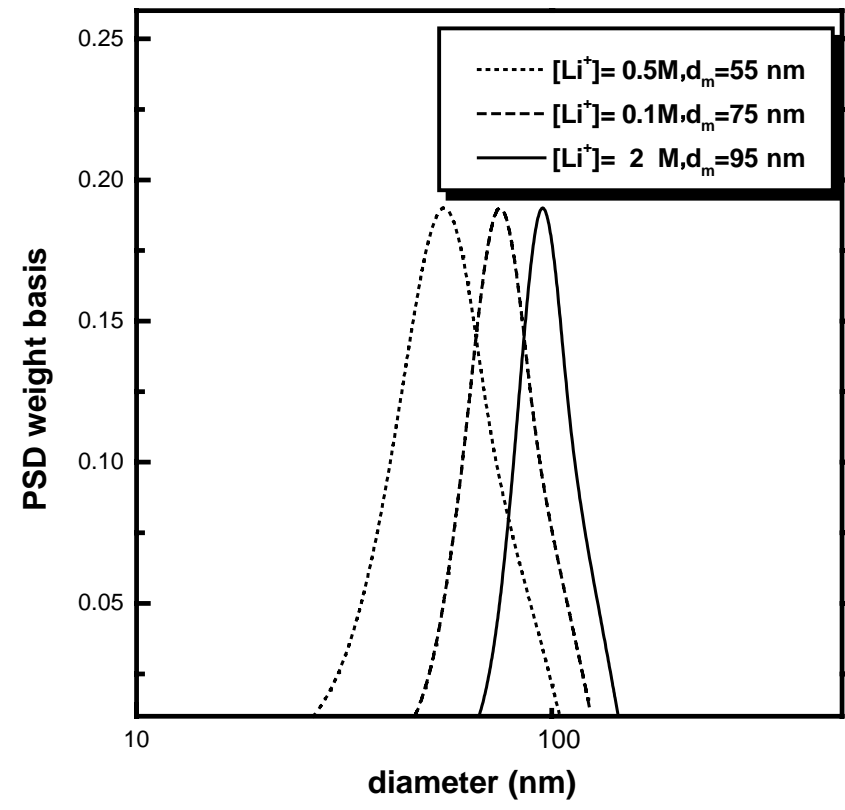

Fig. 2. Size distribution of micelles containing various concentrations of cations.

the improved homogeneity of constituents and the enhanced reactivity of the microemulsion-derived precursors.

\subsection{Effects of the concentration of cations in the aqueous phase on the microstructures of $\mathrm{LiCoO}_{2}$ powders}

The size distribution of micelles with different concentrations of cations in the aqueous phase is illustrated in Fig. 2. In all prepared systems, the size distribution of micelles is narrow. However, the average size of micelles varies with the concentration of cations in the aqueous phase. When the concentration of cations in the aqueous phase increases from 0.5 to $1 \mathrm{M}$, the mean diameter of micelles increases from 55 to $95 \mathrm{~nm}$. The above three kinds of aqueous phase were used to prepare the precursors of $\mathrm{LiCoO}_{2}$ via the microemulsion process. The obtained precursors were dried at $400{ }^{\circ} \mathrm{C}$, and were investigated via TEM. According to the TEM analysis, when the concentration of the aqueous phase increases from 0.5 to $1 \mathrm{M}$, the average particle size of powders increases from 25 to $52 \mathrm{~nm}$. It is found that the size of obtained powders reflects the size of micelles. When the size of micelles increases, the size of powders will also increases correspondingly.

The TEM images of $800^{\circ} \mathrm{C}$-calcined $\mathrm{LiCoO}_{2}$ powders prepared from different concentrations of cations in the aqueous phase are shown in Fig. 3. As seen in this figure, the particle size increases correspondingly with a rise in the concentration of cations in the aqueous phase. As the concentration of the aqueous phase increases from 0.5 to $1 \mathrm{M}$, the average particle size of $\mathrm{LiCoO}_{2}$ powders increases from 100 to $270 \mathrm{~nm}$. It is evident that nanosized $\mathrm{LiCoO}_{2}$ powders are synthesized via the microemulsion process. The dependence of the particle size of $\mathrm{LiCoO}_{2}$ powders on 

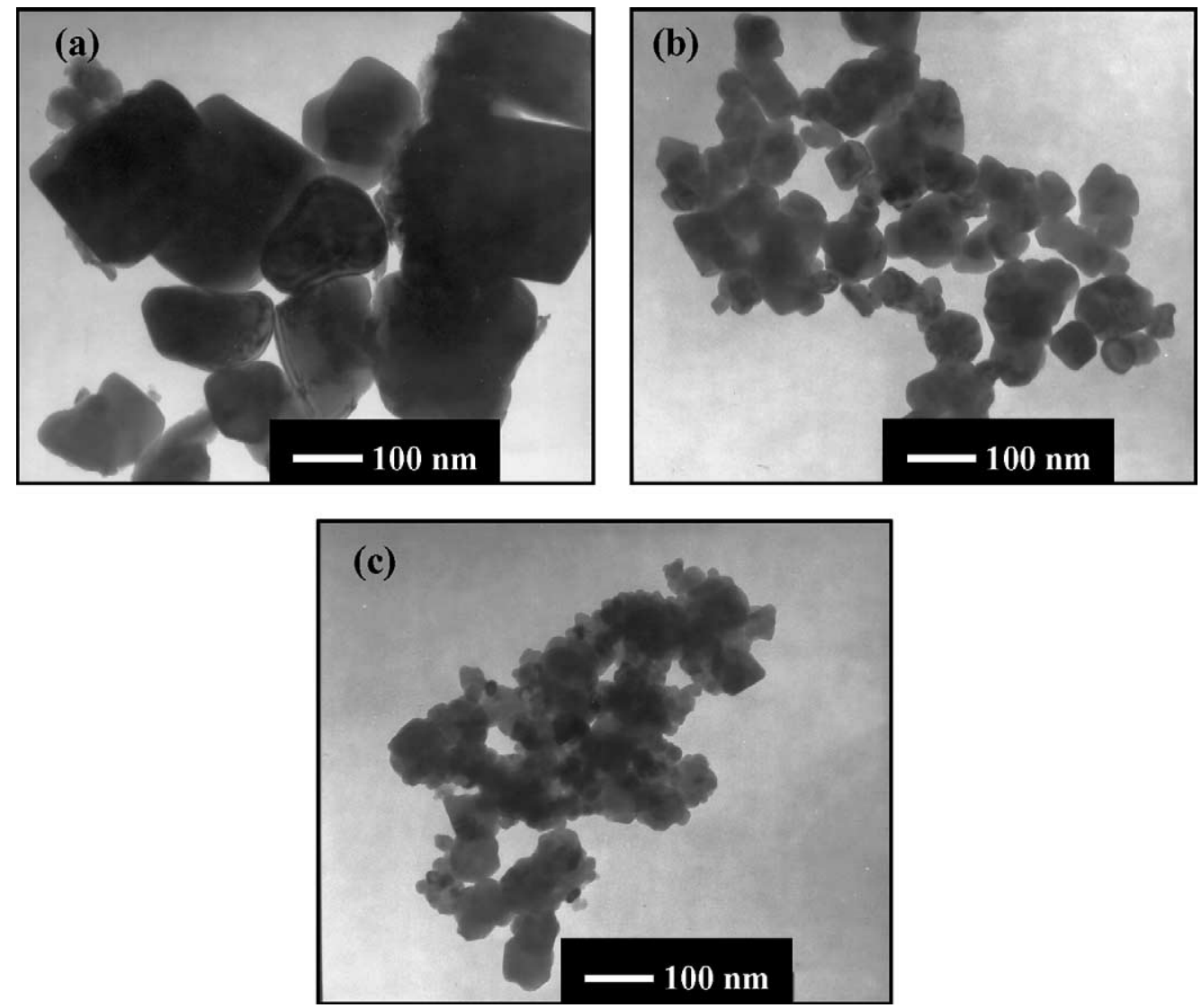

Fig. 3. TEM images of $800^{\circ} \mathrm{C}$ calcined $\mathrm{LiCoO}_{2}$ powders: (a) $\left[\mathrm{Li}^{+}\right]=2 \mathrm{M}$, (b) $\left[\mathrm{Li}^{+}\right]=1 \mathrm{M}$, and (c) $\left[\mathrm{Li}^{+}\right]=0.5 \mathrm{M}$.

the concentration of cations in the aqueous phase and the heating temperature is illustrated in Fig. 4. For all systems, the particle size of $\mathrm{LiCoO}_{2}$ powders increases rapidly with a rise in the heating temperature. At the same heating temperature, raising the concentration of cations in the aqueous phase effectively increases the particle size of $\mathrm{LiCoO}_{2}$ powders. As seen in Fig. 4(c), $\mathrm{LiCoO}_{2}$ particles prepared from the concentration of cations equal to $0.5 \mathrm{M}$ agglomerate seriously. The agglomeration state as well as the particle size of the prepared powders will affect the electrochemical properties of cathode powders.

\subsection{Electrochemical properties of microemulsion-derived $\mathrm{LiCoO}_{2}$ powders}

Fig. 5 illustrates the charge-discharge curves of $800^{\circ} \mathrm{C}$ calcined $\mathrm{LiCoO}_{2}$ powders prepared from different concentrations of cations in the aqueous phase. All obtained powders clearly display a plateau at $3.9 \mathrm{~V}$, which represents the typical electrochemical characteristic of $\mathrm{LiCoO}_{2}$. The discharge capacities in the first cycle of $\mathrm{LiCoO}_{2}$ powders prepared from the concentration of cations in the aqueous phase equal to $0.5,1$, and $2 \mathrm{M}$ are 114,137 , and $128 \mathrm{mAh} / \mathrm{g}$, respectively. It reveals that both the particle size and agglomeration state of $\mathrm{LiCoO}_{2}$ powders will influence the discharge

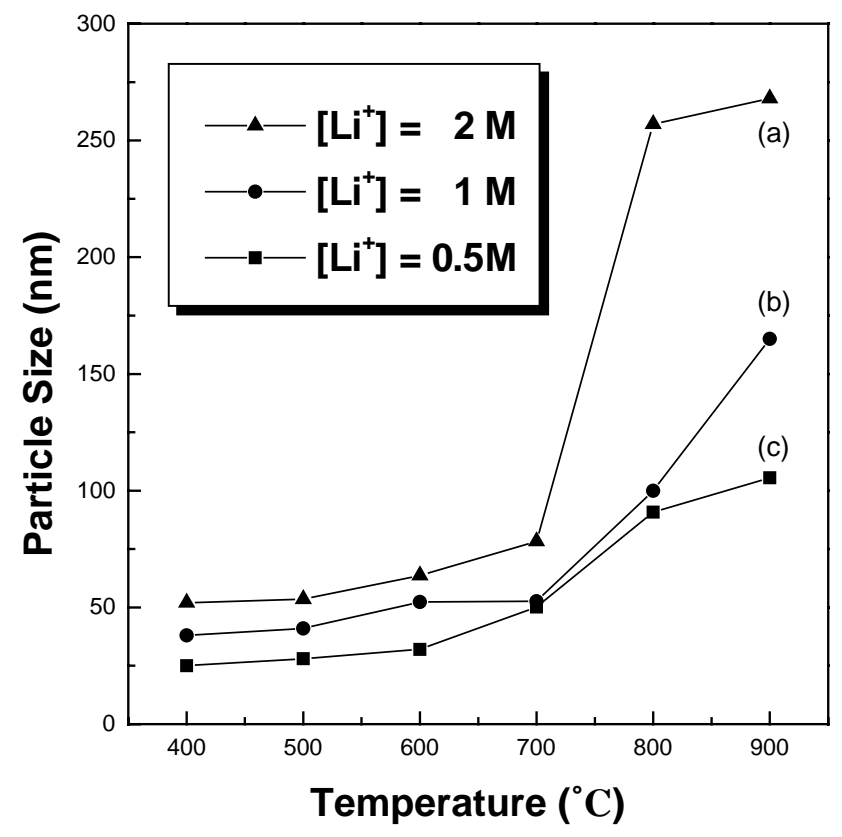

Fig. 4. Relation of the particle size of $\mathrm{LiCoO}_{2}$ powders and the concentration of cations in the aqueous phase as well as the heating temperature. 


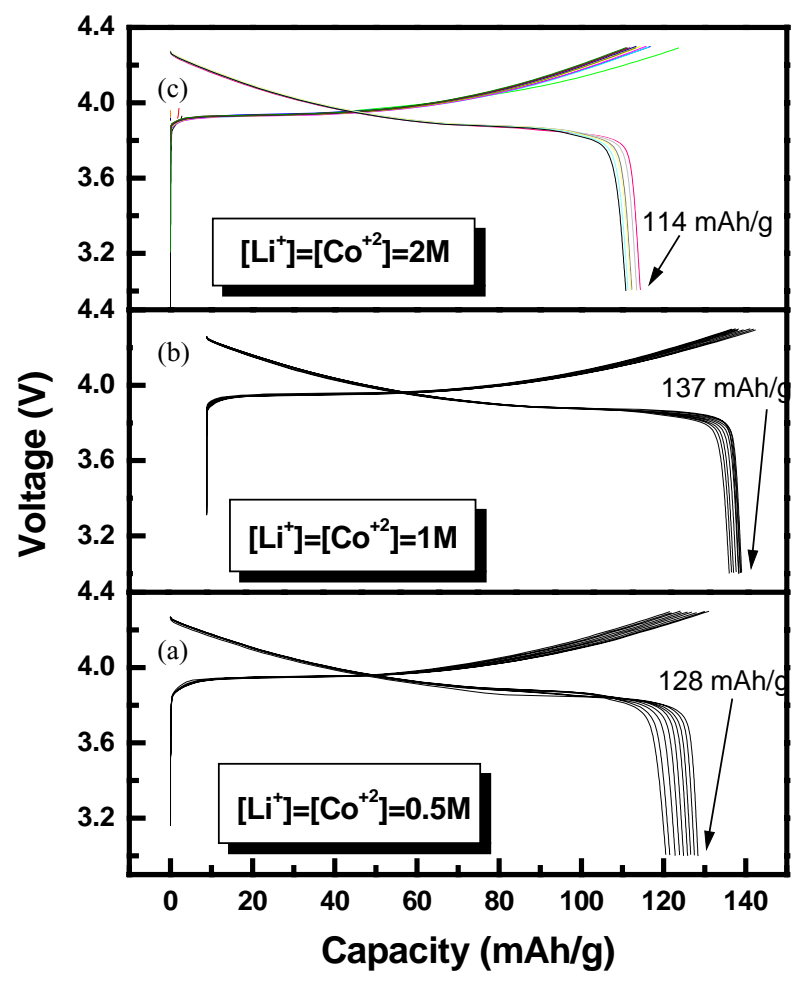

Fig. 5. Charge and discharge curves of the microemulsion-derived $\mathrm{LiCoO}_{2}$ powder obtained at various cationic concentrations: (a) $0.5 \mathrm{M}$, (b) $1.0 \mathrm{M}$, and (c) $2 \mathrm{M}$.

capacities during the electrochemical reactions. When the concentration of cations in the aqueous phase is equal to $1 \mathrm{M}$, the particle size of the prepared $\mathrm{LiCoO}_{2}$ powders is small, and the powders are well dispersed as seen in Fig. 4(b); therefore a high discharge capacity is achieved. When the

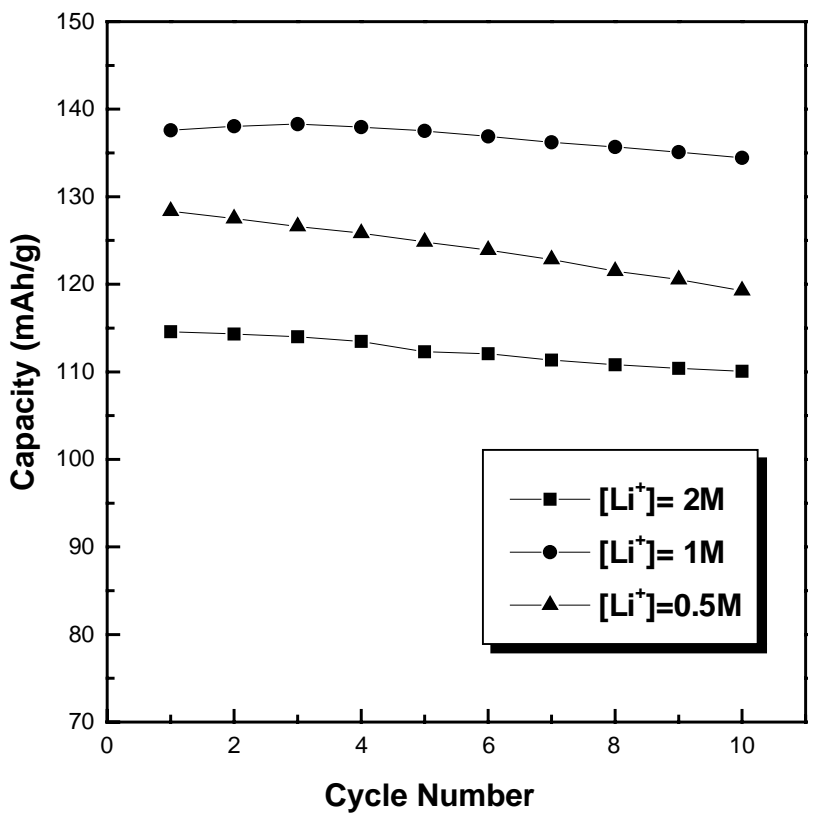

Fig. 6. Discharge capacity vs. cycle number for the microemulsion-derived $\mathrm{LiCoO}_{2}$ powders. concentration of cations in the aqueous phase is equal to $0.5 \mathrm{M}$, agglomerated powders are formed. It is considered that the carbon black and binder cannot be well mixed with cathode materials, thereby reducing the discharge capacity. The relation between specific capacity and cycle number is plotted in Fig. 6. It reveals that good cycleability can be obtained in the microemulsion-derived $\mathrm{LiCoO}_{2}$ powders. The developed method can also be applied to other kinds of cathode materials for controlling their particles size and morphology.

\section{Conclusions}

$\mathrm{LiCoO}_{2}$ powders have been synthesized via a developed microemulsion process in this study. Monophasic powders with a layered $(R \overline{3} m)$ structure are obtained. The concentration of cations in microemulsion not only affects the size of micelles but also the particle size of $\mathrm{LiCoO}_{2}$ powders. An increase in the cationic concentration of the aqueous phase results in an increase in the size of the micelles. Nanosized and well dispersed $\mathrm{LiCoO}_{2}$ powders are formed. The electrochemical analysis indicates that the discharge capacity of $\mathrm{LiCoO}_{2}$ depends on the particle size and agglomeration state of the synthesized powders.

\section{References}

[1] M.G.S.C. Thomas, P.G. Bruce, J.B. Goodenough, AC impedance analysis of polycrystalline insertion electrodes: application to $\mathrm{Li}_{1-x} \mathrm{CoO}_{2}$, J. Electrochem. Soc. 132 (1985) 1521-1528.

[2] G.G. Amatucci, J.M. Taraacon, D. Larcher, L.C. Klein, Synthesis of electrochemically active $\mathrm{LiCoO}_{2}$ and $\mathrm{LiNiO}_{2}$ at 100 degrees $\mathrm{C}$, Solid State Ionics 84 (1996) 169-180.

[3] Y.M. Chang, Y.I. Jang, H. Wang, B. Huang, D.R. Sadoway, P. Ye, Synthesis of $\mathrm{LiCoO}_{2}$ by decomposition and intercalation of hydroxides, J. Electrochem. Soc. 145 (1998) 887-891.

[4] E. Plichta, M. Salomon, S. Slane, M. Uchiyama, D. Chua, W.B. Ebner, H.W. Lin, An improved $\mathrm{Li} / \mathrm{Li}_{x} \mathrm{CoO}_{2}$ rechargeable cell, J. Electrochem. Soc. 136 (1989) 1865-1869.

[5] S. Wada, T. Suzuki, T. Noma, The effect of the particle sizes and the correlational sizes of dipoles introduced by the lattice-deffects on the crystal-structure of barium-titanate fine particles, J. Ceram. Soc. Jpn. 103 (1995) 5368-5379.

[6] G.H. Maher, C.E. Hutchins, S.D. Ross, Preparation and characterization of ceramics fine powders produced by the emulsion process, Am. Ceram. Soc. Bull. 72 (1993) 72-76.

[7] W. Liu, G.C. Farrington, F. Chaput, B. Dunn, Synthesis and electrochemical studies of spinel phase $\mathrm{LiMn}_{2} \mathrm{O}_{4}$ cathode materials prepared by the Pechini process, J. Electrochem. Soc. 143 (1996) 879-884.

[8] X. Qiu, X. Sun, W. Shen, N. Chen, Spinel $\mathrm{Li}_{1+x} \mathrm{Mn}_{2} \mathrm{O}_{4}$ synthesized by coprecipitation as cathodes for lithium-ion batteries, Solid State Ionics 93 (1997) 335-339.

[9] V. Jayaraman, T. Gnanasekaran, G. Periaswami, Low-temperature synthesis of beta-aluminas by a sol-gel technique, Mater. Lett. 30 (1997) 157-162.

[10] C.H. Lu, Y.P. Yeh, Microstructural development and electrochemical characteristics of lithium cobalt oxide powders prepared by the water-in-oil emulsion process, J. Eur. Ceram. Soc. 22 (2002) 673679 
[11] C.H. Lu, Y. Lin, Influence of the emulsification conditions on the microstructures and electrochemical characteristics of spinel lithium manganese oxide powders, J. Mater. Res. 18 (2003) 552-559.

[12] C.H. Lu, H.C. Wang, Synthesis of nano-sized $\mathrm{LiNi}_{0.8} \mathrm{Co}_{0.2} \mathrm{O}_{2}$ via a reverse-microemulsion route, J. Mater. Chem. 13 (2003) 428-431.
[13] Powder Diffraction File, Card No. 44-145, Joint Committee on Powder Diffraction Standards, Swarthmore, PA.

[14] K. Mizushima, P.C. Jones, P.J. Wiseman, J.B. Goodenough, Mater. Res. Bull. 15 (1980) 783. 